\title{
Dual-Channel Circuit Mapping Reveals Sensorimotor Convergence in the Primary Motor Cortex
}

\author{
Bryan M. Hooks, ${ }^{1,2}$-John Y. Lin, ${ }^{3,4}$ Caiying Guo, ${ }^{1}$ and Karel Svoboda ${ }^{1}$ \\ ${ }^{1}$ Janelia Research Campus, Howard Hughes Medical Institute, Ashburn, Virginia 20147, ${ }^{2}$ University of Pittsburgh School of Medicine, Department of \\ Neurobiology, Pittsburgh, Pennsylvania 15213, 32Department of Pharmacology, University of California San Diego, San Diego, California 92093, and \\ ${ }^{4}$ University of Tasmania School of Medicine, Hobart, Tasmania 7000, Australia
}

Cortical cells integrate synaptic input from multiple sources, but how these different inputs are distributed across individual neurons is largely unknown. Differences in input might account for diverse responses in neighboring neurons during behavior. We present a strategy for comparing the strengths of multiple types of input onto the same neuron. We developed methods for independent dualchannel photostimulation of synaptic inputs using ChR2 together with ReaChR, a red-shifted channelrhodopsin. We used dual-channel photostimulation to probe convergence of sensory information in the mouse primary motor cortex. Input from somatosensory cortex and thalamus converges in individual neurons. Similarly, inputs from distinct somatotopic regions of the somatosensory cortex are integrated at the level of single motor cortex neurons. We next developed a ReaChR transgenic mouse under the control of both Flp- and Cre-recombinases that is an effective tool for circuit mapping. Our approach to dual-channel photostimulation enables quantitative comparison of the strengths of multiple pathways across all length scales of the brain.

Key words: circuit mapping; dual-channel stimulation; motor cortex; optogenetics; ReaChR; somatosensory cortex

\section{Introduction}

The mammalian nervous system is a network of many brain regions, each containing diverse cell types receiving multiple sources of input. Within each brain region, even pyramidal neurons of one type show diverse behavior-related dynamics (O'Connor et al., 2010; Harvey et al., 2012). Understanding the underlying circuit mechanisms requires comparison of the functional strengths of multiple sources of input to individual neurons. Exciting specific inputs is challenging in brain regions where axons of different types are spatially intermingled. ChR2 (Nagel et al., 2003) and related molecules (Mattis et al., 2012) allow excitation of defined populations of neurons. ChR2 provides a powerful method for mapping functional connections throughout the brain (Petreanu et al., 2007). Thus, extending circuit mapping to two independent channels for comparison of multiple pathways is of considerable interest.

Several opsins with differing excitation spectra have been introduced (Zhang et al., 2008; Yizhar et al., 2011; Lin et al., 2013). Although red-shifted opsins can be readily excited with orange or

Received Sept. 6, 2014; revised Feb. 2, 2015; accepted Feb. 8, 2015.

Author contributions: B.M.H. and K.S. designed research; B.M.H. and C.G. performed research; B.M.H., J.Y.L., and C.G. contributed unpublished reagents/analytic tools; B.M.H. analyzed data; B.M.H. and K.S. wrote the paper.

This work was supported by the Howard Hughes Medical Institute and the National Institutes of Health Grant NSO27177. We thank Gordon Shepherd, YingXin (Wendy) Zhang, Nick Sofroniew, Nuo Li, Zengcai Guo, Leopoldo Petreanu, Justin Little, and other members of the K.S. laboratory for comments and suggestions; Susan Michael and Monique Copeland for histology preparation; and Roger Tsien for providing the ReaChR constructs.

The authors declare no competing financial interests.

Correspondence should be addressed to either Dr. Bryan M. Hooks or Dr. Karel Svoboda, Janelia Research Campus, Howard Hughes Medical Institute, 19700 Helix Drive, Ashburn, VA 20147. E-mail: hooksm@janelia.hhmi.org or svobodak@janelia.hhmi.org.

DOI:10.1523/JNEUROSCI.3741-14.2015

Copyright $\odot 2015$ the authors $\quad 0270-6474 / 15 / 354418-09 \$ 15.00 / 0$ red light independent of ChR2, the fundamental challenge in separating two channels is that all opsins, including ChR2 and red-shifted variants, are activated by blue light. Independent activation of two opsins has been achieved using excitation of a fast ChR2 variant with short blue light pulses, which are unable to drive the kinetically slower red-shifted opsin (Klapoetke et al., 2014). However, this approach requires tight control of expression level and light intensity that are difficult to achieve with viral injections in intact tissue.

Here we show that axons expressing ChR2 or ReaChR (Lin et al., 2013) become inactivated by prolonged excitation of the light-gated channel. This allowed us to photostimulate axons expressing the red-shifted channel, while later blocking activation of that channel when axons expressing the blue-shifted channel were photostimulated. Thus, ReaChR together with ChR2 allows independent excitation of distinct axonal populations in the same experiment. To facilitate circuit mapping with ReaChR, we developed a transgenic mouse expressing ReaChR in a Flp- and Cre-recombinase-dependent manner. Compared with viral gene transfer, this mouse provides more uniform and repeatable expression levels. We then explored convergence of input from primary sensory cortex (vS1) and thalamus (POm) to vibrissal primary motor cortex (vM1), an area where these axonal projections anatomically overlap (Kaneko et al., 1994; Brecht et al., 2004; Mao et al., 2011; Ohno et al., 2012; Hooks et al., 2013).

\section{Materials and Methods}

All experimental protocols were conducted according to National Institutes of Health guidelines for animal research and were approved by the Institutional Animal Care and Use Committee at Howard Hughes Medical Institute Janelia Research Campus. 
Stereotaxic injections. Juvenile (postnatal day P12-P19) mice of either sex were anesthetized and injected with adeno-associated virus (AAV; CAG promoter, serotype $2 / 1$ or $2 / \mathrm{rh} 10$, AAV-ChR2-XFP in the text) expressing ChR2-mVenus or ChR2-tdTomato (www.addgene.com; plasmids 20071 and 28017) as well as ReaChR-expressing AAV (synapsin promoter, serotype $2 / 1$ or $2 / 8,2.2 \mathrm{E} 13 \mathrm{GC} / \mathrm{ml}$ titer, ReaChR-mCit in the text; www.addgene.com; plasmid 50954) (Lin et al., 2013). C1V1expressing virus in control experiments was also AAV (CaMKIIa promoter, serotype 2/1, 6.6E13 GC/ml titer; C1V1(T/T)-eYFP; www. addgene.com; plasmid 35499) (Yizhar et al., 2011). The injection apparatus was a custom-made positive displacement pump allowing nanoliter volumes to be injected slowly. Stereotactic coordinates are as in previous studies (Hooks et al., 2013). As in our previous studies, we examined the injection site in thalamus during sectioning to confirm thalamic targeting to POm. We also confirmed the axonal projection pattern in cortex was typical of POm injections (Petreanu et al., 2009; Hooks et al., 2013). One bolus $(30 \mathrm{nl})$ was injected into thalamic targets; a pair of injections (30 nl each; 500 and $800 \mu \mathrm{m}$ deep) was made into cortical targets.

Electrophysiology and photostimulation. Brain slices were prepared $\sim 2$ weeks after viral infection (Mao et al., 2011) at P28-P39 for AAVinjected mice or P46-P54 for transgenic mice. The $300 \mu \mathrm{m}$ off-coronal sections of vM1 were cut using a vibratome (HM $650 \mathrm{~V}$, Microm) in cooled choline-based cutting solution (in $\mathrm{mm}$ as follows: 110 choline chloride, 3.1 sodium pyruvate, 11.6 sodium ascorbate, $25 \mathrm{NaHCO}_{3}, 25$ D-glucose, $7 \mathrm{MgCl}_{2}, 2.5 \mathrm{KCl}, 1.25 \mathrm{NaH}_{2} \mathrm{PO}_{4}, 0.5 \mathrm{CaCl}_{2}$ ). Coronal sections were used for vS1 recordings. Slices were incubated at $37^{\circ} \mathrm{C}$ in oxygenated ACSF (in mM as follows: $127 \mathrm{NaCl}, 25 \mathrm{NaHCO}_{3}, 25$ D-glucose, $2.5 \mathrm{KCl}, 2$ $\mathrm{CaCl}_{2}, 1 \mathrm{MgCl}_{2}, 1.25 \mathrm{NaH}_{2} \mathrm{PO}_{4}$ ) for $>30 \mathrm{~min}$ and maintained at room temperature $\left(22^{\circ} \mathrm{C}\right)$ thereafter. Our recording site in vM1 corresponds to AgM in rat (Brecht et al., 2004).

Whole-cell recordings were performed at $30^{\circ} \mathrm{C}-33^{\circ} \mathrm{C}$ in oxygenated ACSF with borosilicate pipettes (3-6 M 2 ; Warner Instruments) containing potassium gluconate-based internal solution (in mM as follows: 128 potassium gluconate, $4 \mathrm{MgCl}_{2}, 10$ HEPES, 1 EGTA, $4 \mathrm{Na}_{2} \mathrm{ATP}, 0.4$ $\mathrm{Na}_{2} \mathrm{GTP}, 10$ sodium phosphocreatine, 3 sodium L-ascorbate; $\mathrm{pH}$ 7.27; $287 \mathrm{mOsm})$. Biocytin was added to the intracellular solution $(3 \mathrm{mg} / \mathrm{ml})$ for later reconstruction of dendritic morphology. Experiments were typically performed in voltage clamp at $-70 \mathrm{mV}$, except for controls for axonal excitability (see Fig. $1 I, J$ ). In a subset of current-clamp experiments, EPSP depolarization ranged from 4 to $12 \mathrm{mV}$ for pyramidal neurons with typical EPSC amplitudes ( 300 or $800 \mathrm{pA}$ ). Although long-range excitatory input did not typically drive pyramidal neurons to action potential threshold, we did observe the recruitment of feedforward inhibition in voltage clamp recordings at $0 \mathrm{mV}$. In some experiments, such as recording direct ChR2 or ReaChR currents, TTX (1 $\mu \mathrm{M}$, Tocris Bioscience), NBQX (10 $\mu \mathrm{M}$, Tocris Bioscience), and CPP (5 $\mu \mathrm{M}$, Tocris Bioscience) were added to the bath. LED pulses were controlled using the Cairn OptoLED system. LEDs of 590 and $470 \mathrm{~nm}$ were used for photostimulation. Photostimuli in single-channel experiments were $\sim 2 \mathrm{~mW} / \mathrm{mm}^{2}$. For 2-channel ChR-Assisted Circuit Mapping (2CRACM) experiments, to evoke maximum responses from both pathways when expression levels differed, photostimulus intensity was increased several-fold by switching from a $4 \times 10.16 \mathrm{NA}$ to a $60 \times / 0.9 \mathrm{NA}$ objective, increasing light intensity to $\sim 31 \mathrm{~mW} / \mathrm{mm}^{2}$. Photon flux was always matched for $590 \mathrm{~nm}$ and $470 \mathrm{~nm}$ stimuli in the same experiment. Light $<585 \mathrm{~nm}$ from the 590 nm LED was blocked using a bandpass filter (D607/45, Chroma). Data were acquired at $10 \mathrm{kHz}$ using an Axopatch 700B (Molecular Devices) and Ephus software (www.ephus.org) (Suter et al., 2010) on a custombuilt laser scanning photostimulation microscope (Shepherd et al., 2003). Individual trials were repeated $\sim 5$ times and averaged. Electrophysiology data were low pass filtered offline $(1 \mathrm{kHz})$. Data analysis was performed with custom routines written in MATLAB (MathWorks).

Anatomy and imaging. Mice were injected in vS1 with AAV2/1ReaChR-mCitrine, AAV2/1-ChR2-mVenus, and AAV2/1-C1V1-EYFP to characterize trafficking of the three opsins. Two weeks after injection, mice were transcardially perfused and $100 \mu \mathrm{m}$ coronal sections imaged on the LSM710 confocal (Carl Zeiss) using a $20 \times / 0.8$ NA PlanApochromat objective. The $400 \mu \mathrm{m} \times 400 \mu \mathrm{m}$ tiled images covered the thickness of cortex. Laser power was set for each mouse to result in saturation of $<1 \%$ of pixels at the injection site. The same laser power was used to image VPM and POm (the brightest axonal projection); laser power was increased $4 \times$ to image less bright axons in vM1, superior colliculus, and pons. Where axonal projections were not apparent, the stereotaxically corresponding brain region was imaged. Fluorescence values at the injection site were determined by summing all pixels in a 100 $\mu \mathrm{m}$ section and subtracting pixels less than background (where background was the mean fluorescence $+6 \mathrm{SD}$ of values in an adjacent region of the image). Fluorescence values at the projection zone were similarly determined and normalized by division with the injection site fluorescence of that animal.

Generation of transgenic ReaChR mice. Targeting constructs derived from ReaChR-mCitrine were generated and cloned into the Rosa26pCAG-FSF-LSL-ReaChR-mCit-WPRE-pA targeting vector (Dymecki and Kim, 2007; Madisen et al., 2012). Separate constructs using ReaChR2A-mCitrine were also generated but produced inferior expression for unknown reasons. The targeting vectors were transfected into ES cells and chimeric mice developed using successfully transfected ES clones. The resulting reporter mice were bred to Rosa26-PhiC31 mice to remove the neomycin cassette, as well as Rosa26-CAG-Flp or Rosa26-CAG-Cre mice to eliminate dependence of transgene expression on one or both recombinases. ReaChR expression was evaluated both by native fluorescence and functional assays. Rosa26-pCAG-FSF-LSL-ReaChR-mCit mice were submitted to The Jackson Laboratory (stock \#024846, Rosa26 CAG-FSF-LSL-ReaChRmCit; stock \#026294 Rosa26 CAG-LSL-ReaChR-mCit).

\section{Results}

\section{Selective photostimulation of ReaChR}

To develop 2CRACM, we first identified a red-shifted channelrhodopsin that could be activated with long wavelength light without activation of ChR2 (Zhang et al., 2008; Yizhar et al., 2011). ReaChR is an engineered chimeric protein with enhanced activation by red light (Lin et al., 2013). We used AAV to express ReaChR-mCitrine in cortical pyramidal neurons. Photostimulation with 470 or $590 \mathrm{~nm}$ light evoked a rapid-onset inward current from ReaChR-positive neurons (ReaChR+; Fig. 1A). ReaChR currents peaked $64.5 \pm 10.1 \mathrm{~ms}$ after light onset and decayed to a plateau level $\left(82.2 \pm 15.8 \%\right.$ of peak; $\left.2 \mathrm{~mW} / \mathrm{mm}^{2}\right)$. Neurons expressing ReaChR had normal resting potentials, independent of the maximum current that could be evoked, indicating that they were healthy (Vrest for ReaChR + neurons, $-65.1 \pm$ $3.8 \mathrm{mV}, N=10$; adjacent ReaChR- neurons, $-63.3 \pm 5.2 \mathrm{mV}$, $N=4$ ). ReaChR peak and plateau amplitudes were similar for both stimulation wavelengths over a large range of intensities (Fig. 1B). The rise time was slightly faster for $470 \mathrm{~nm}$ photostimuli $(470 \mathrm{~nm}, 39.3 \pm 2.6 \mathrm{~ms} ; 590 \mathrm{~nm}, 64.5 \pm 10.1 \mathrm{~ms} ; p<$ $0.005, t$ test). In contrast, ChR2-positive pyramidal neurons $(\mathrm{ChR} 2+)$ responded to $470 \mathrm{~nm}$, but not to $590 \mathrm{~nm}$, photostimuli (Fig. 1C,D).

We next compared ChR2 and ReaChR for CRACM, which relies on axonal expression of the light-gated channel. We compared expression and axonal transport of ReaChR-mCitrine, ChR2mVenus, and C1V1-EYFP by injecting AAV into vS1 (Fig. 2A-C). After 2 weeks of expression, we made confocal images of fixed sections at the injection site and five regions targeted by vS1 axons. As with ChR2, ReaChR-mCit is transported effectively into axons, and bright fluorescent axons can be seen in cortex, thalamus, and brainstem (Fig. 2B,D). Quantification of normalized axon fluorescence revealed that long-range projections to VPM and vM1 were 10 $100 \times$ brighter for ChR $2+$ and ReaChR + axons than for C1V1 (Fig. 2C).

We infected neurons in vS1 using either AAV-ReaChR-mCit or AAV-ChR2-XFP to test the effectiveness of ReaChR for axonal photostimulation. We then recorded layer 2/3 (L2/3) pyramidal neurons in brain slices of vM1, a layer receiving input from vS1 
A<smiles>COC(C)(C)C</smiles> \\ Direct \\ ReaChR+}
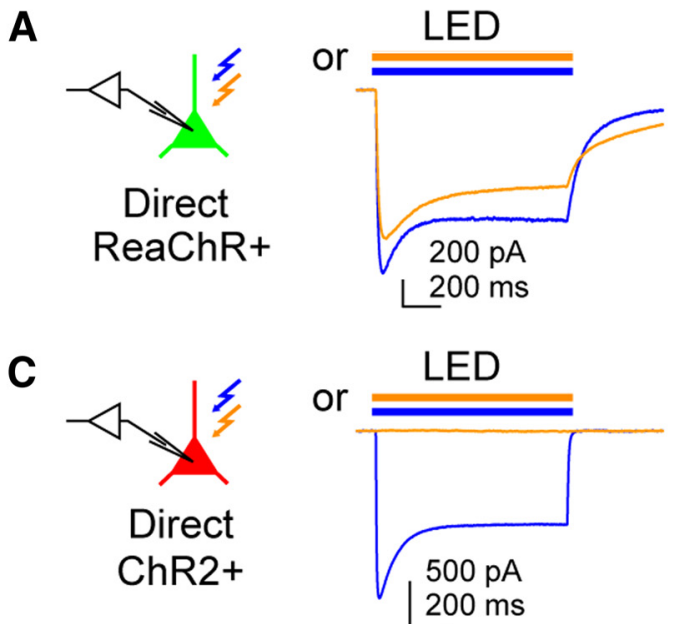

E
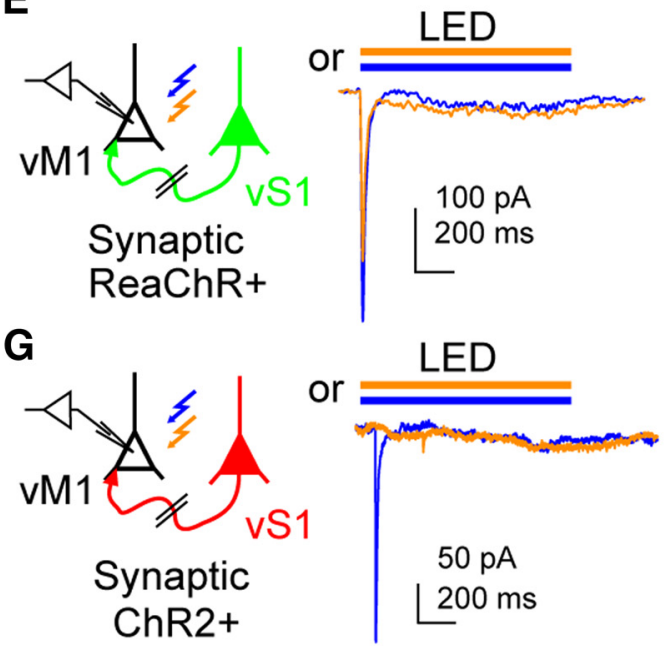

B
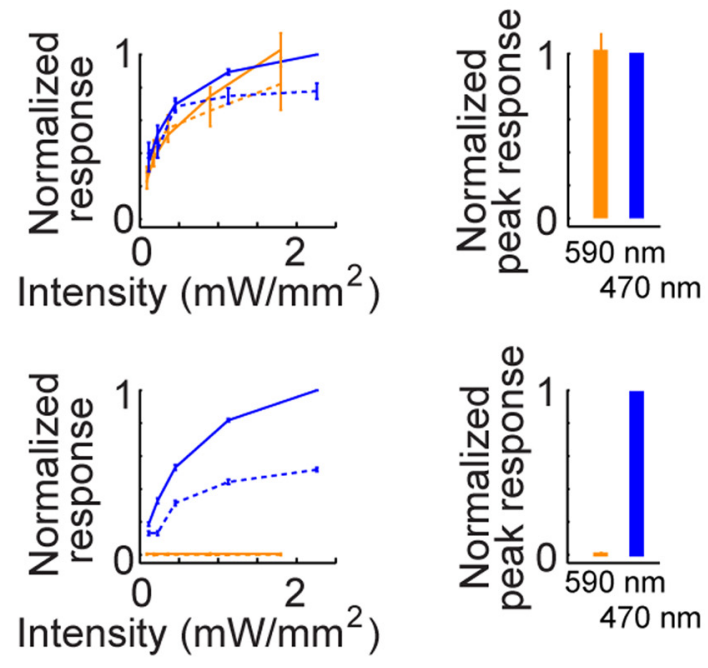

$\mathbf{H}$
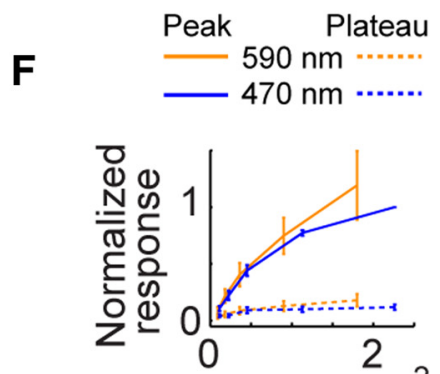

Intensity $\left(\mathrm{mW} / \mathrm{mm}^{2}\right)$
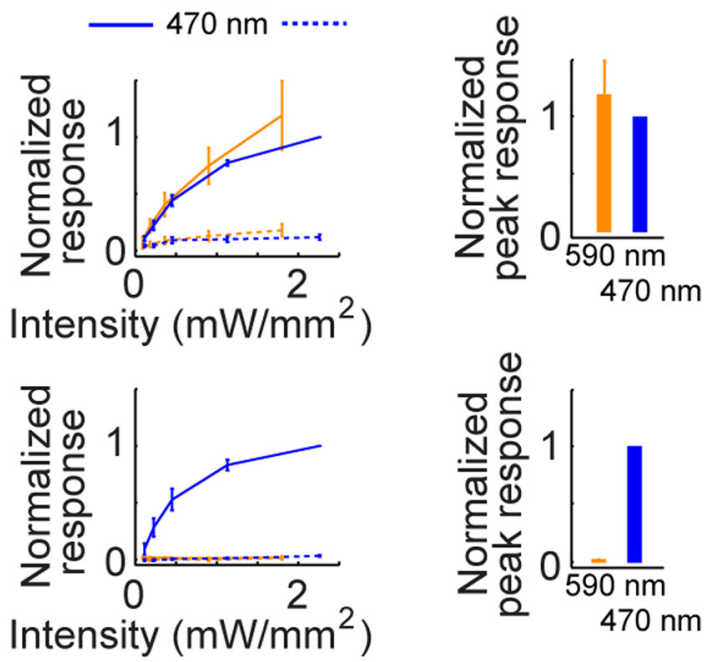

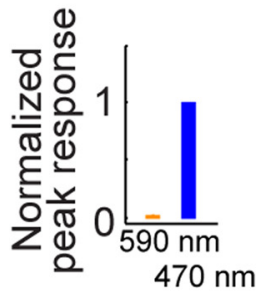

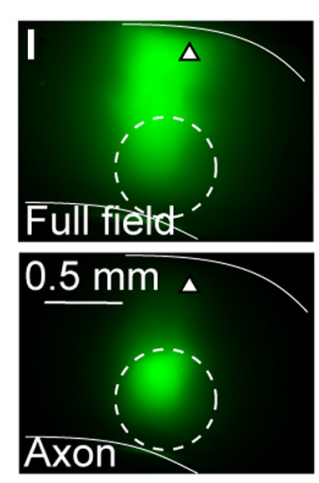
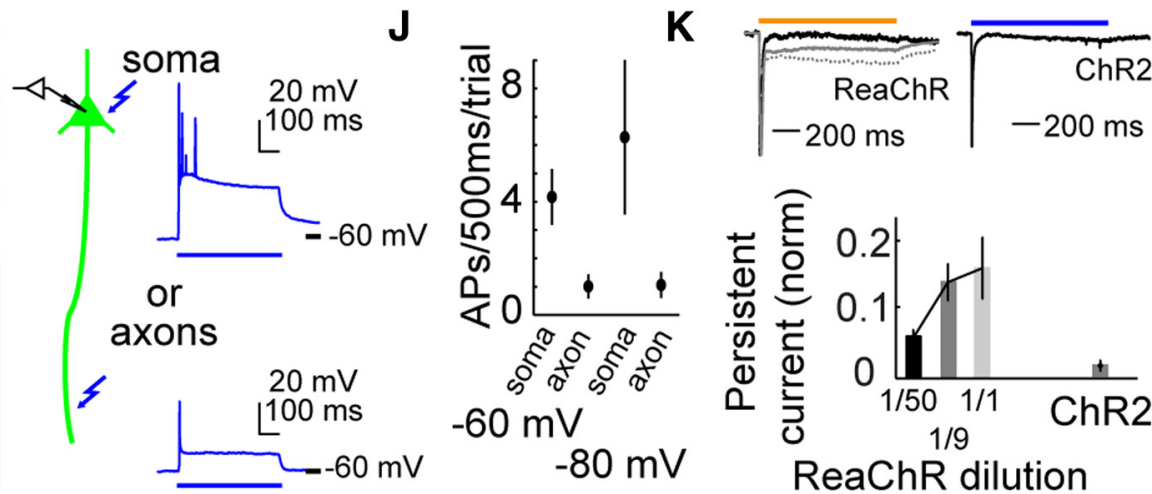

Figure 1. ReaChR responds to blue and orange light, whereas ChR2 responds only to blue light. $A, B$, Direct ReaChR currents in vS1 pyramidal neurons. $A$, Response to 1 s photostimuli of $590 \mathrm{~nm}$ (orange) or $470 \mathrm{~nm}$ (blue) of matched photon flux $\left(5.3 \times 10^{15}\right.$ photons $\left./ \mathrm{s} \mathrm{mm}^{2} ; \sim 2 \mathrm{~mW} / \mathrm{mm}^{2}\right)$. ReaChR currents were isolated from intrinsic and synaptic currents by $1 \mu \mathrm{M}$ TTX, $10 \mu \mathrm{m} \mathrm{NBQX,} \mathrm{and} 5 \mu \mathrm{m}$ CPP. B, Left, Amplitude of peak (solid) and plateau responses (dashed line indicates mean of last $100 \mathrm{~ms}$ of photostimulus), normalized to the $470 \mathrm{~nm}$ peak. Error bars indicate SEM. Right, Peak response atmaximum intensity. $N=5$ neurons. $C, D$, Same as above for direct ChR2 currents. $N=8$ neurons. $E$, $F$, Synaptic responses in vM1 pyramidal neurons caused by photostimulation of ReaChR+ axons. $E$, Left, Diagram of vS1 injection and VM1 recording. Right, Postsynaptic response to $1 \mathrm{~s}$ photostimuli. $F$, Left, Amplitude of normalized peak response (solid). Plateau responses (dashed) are quantified during the same time window as for direct responses. Right, Peak response at maximum intensity. $N=14$ neurons. $\boldsymbol{G}, \boldsymbol{H}$, Same as $\boldsymbol{E}, \boldsymbol{F}$ for ChR2 + vS1 axons. $N=7$ neurons. $\boldsymbol{I}$, Whole-cell current-clamp recordings during prolonged illumination. Fluorescence image of L2/3 vS1 neurons expressing ChR2 under $470 \mathrm{~nm}$ illumination to the full field (somatic excitation; top) or a spot in L5 (axonal excitation; bottom; dotted line). Solid lines indicate pia and white matter. Recording (with $5 \mu \mathrm{m}$ (PP and $10 \mu \mathrm{m} \mathrm{NBQX)} \mathrm{during} 500 \mathrm{~ms}$ somatic or axonal stimulation evokes action potentials (right).J, Resting membrane potential was adjusted to either - $60 \mathrm{mV}$ or -80 $\mathrm{mV}$ by currentinjection. When illumination was restricted to $\mathrm{L} 5$ axons, $\sim 1 \mathrm{AP} /$ trial was evoked at Vrest of $-60 \mathrm{mV}(1.01 \pm 0.39 \mathrm{APs})$ or $-80 \mathrm{mV}(1.06 \pm 0.42 \mathrm{APs})$. AP firing was more persistent during somatic illumination ( $4.17 \pm 0.95 \mathrm{APs} /$ trial at $-60 \mathrm{mV} ; 6.28 \pm 2.69 \mathrm{APS} /$ trial at $-80 \mathrm{mV}) . N=8$ neurons. $\boldsymbol{K}$, High expression levels of ReaChR can induce persistent synaptic release during $1 \mathrm{~s}$ photostimulation. Peak normalized recordings (left, top) for three neurons from animals injected with dilutions of AAV-ReaChR-mCitrine: black represents $1 / 50$; gray represents $1 / 9$; dashed line, $1 / 1$ undiluted $(N=39,9$, and 7 neurons, respectively). Bottom, Quantification of the normalized mean ( \pm SEM) persistent current (last $100 \mathrm{~ms}$ of photostimulation). Top right, $\left(\mathrm{Ch}^{2+}\right.$ axons during prolonged $470 \mathrm{~nm}$ photostimulation. $N=8$ neurons. 


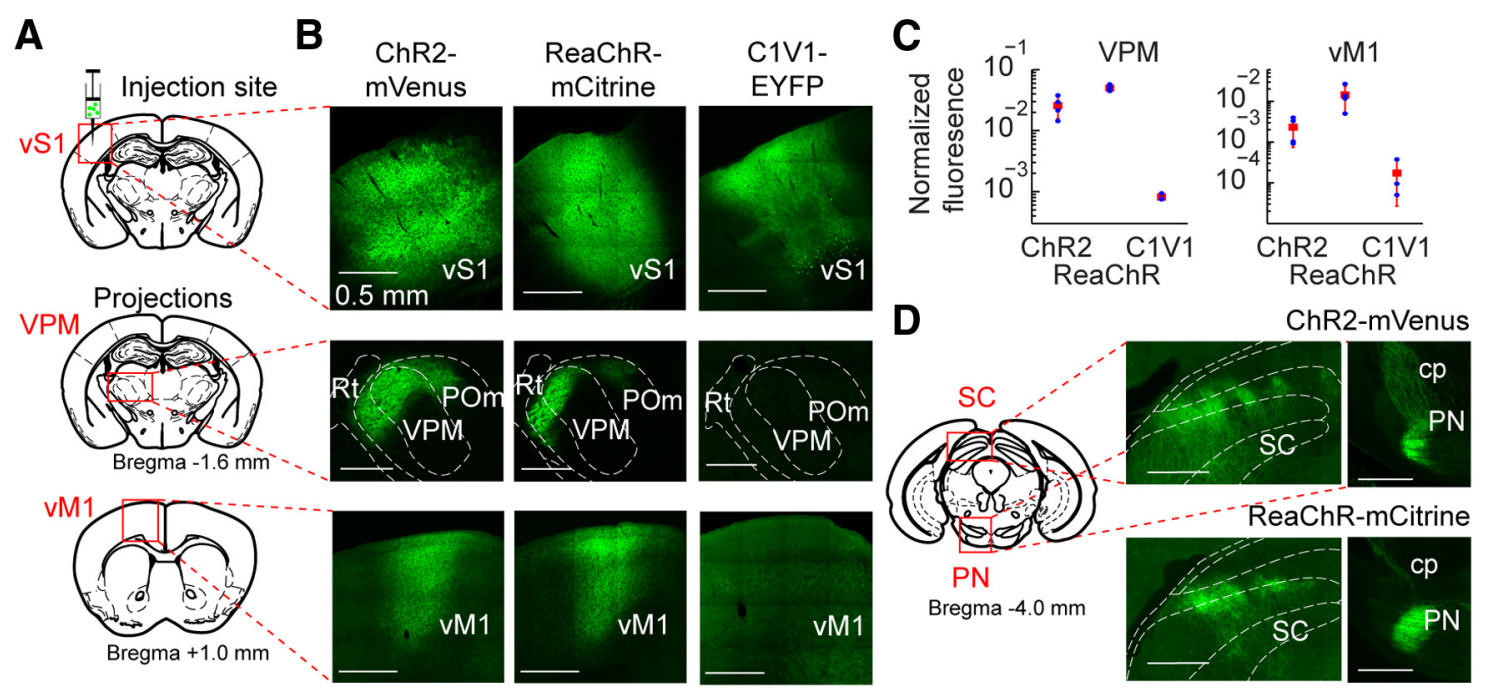

Figure 2. Expression and trafficking of ChR2, ReaChR, and C1V1. A, AAV injection site (green syringe) in vS1 and projections in VPM and vM1 (Paxinos and Franklin, 2004). Animals were injected with AAVs expressing ReaChR-mCitrine, ChR2-mVenus, or C1V1-EYFP and perfused at 14-15 d after injection. B, Confocal microscope images of ChR2, ReachR, and C1V1 expression in vS1, VPM, and VM1 (red boxed areas in $A$ ). Scale bars, all panels: $0.5 \mathrm{~mm}$. C, Quantification of axonal fluorescence to targets in VPM and vM1, normalized by injection site fluorescence and plotted in logarithmic units. Red square and bars represent mean and SD. Blue points indicate individual measurements ( $N=3-6$ slices from 2 or 3 animals per opsin). $D$, Confocal microscope images of long range projections to superior colliculus (SC) and pontine nuclei (PN). Scale bars, all panels: $0.5 \mathrm{~mm}$.
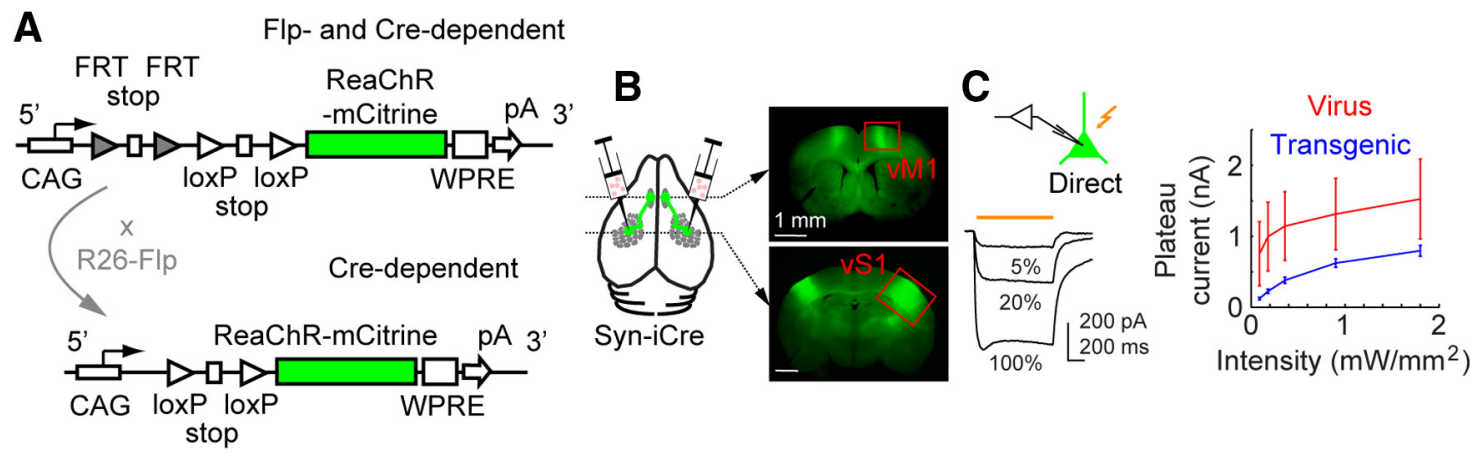

Figure 3. ReaChR reporter mouse development and characterization. $\boldsymbol{A}$, Generation of the Cre and Flp-dependent ReaChR reporter line. Construct includes FRT sites, loxP sites, and ReaChR$\mathrm{mCitrine}$ with WPRE. Cross to Rosa26-Cre or Rosa26-Flp mice makes offspring dependent on one recombinase. B, Bilateral injection of AAV-Syn-iCre into vS1 of heterozygous Rosa26-ReaChR$m$ Citrine (+/-); Rosa26-Flp (+/-) mice. Fluorescence images of $m$ Citrine expression at the injection site (vS1) and axonal projections to vM1. C, Uniformity of ReaChR expression in L2/3 pyramidal neurons of vS1. ReaChR was expressed either transgenically (heterozygous Rosa26-ReaChR-mCitrine mice crossed to Rosa26-Flp with AAV-Syn-iCre injection, $N=7$ ) or virally (using AAV-Syn-ReaChR-mCitrine, $N=5$ ) in vS1 pyramidal neurons and recorded in whole-cell voltage clamp ( $-70 \mathrm{mV}$ ). Example recording at three different LED intensities is shown. The plateau current for transgenic mice (blue) is quantified as in Figure 1 (mean \pm SEM). Red represents viral expression for comparison.

(Mao et al., 2011). Photostimulation of ReaChR+ axons evoked excitatory synaptic currents $\left(\right.$ EPSC $_{\mathrm{CRACM}}$, or $\mathrm{EPSC}_{\mathrm{C}}$ ) with either 470 or $590 \mathrm{~nm}$ light (Fig. $1 E, F)$. EPSC $_{\mathrm{C}}$ had an onset of $5.3 \pm 0.1$ ms following $590 \mathrm{~nm}$ photostimulation $(470 \mathrm{~nm}, 5.6 \pm 0.1 \mathrm{~ms}$; $\sim 2 \mathrm{~mW} / \mathrm{mm}^{2}$ ) and decayed rapidly. Onset time was consistent with optogenetic stimulation in slice (Arenkiel et al., 2007; Petreanu et al., 2007; Kim et al., 2014). In contrast, EPSC $_{C}$ from ChR2 + axons occurred only following $470 \mathrm{~nm}$ photostimulation (Fig. 1G,H). During prolonged photostimulation, axons generated on average one action potential and then ceased firing (Fig. $1 \mathrm{I}, J ; 1.01 \pm 0.39 \mathrm{APs} /$ trial), which likely explains the transient synaptic response to photostimulation. Under conditions of higher ReaChR expression, a small persistent, action potentialindependent synaptic current could be evoked, which was minimized by reducing expression levels (Fig. $1 K$ ). The persistent current can be driven directly by ReaChR in the presence of $1 \mu \mathrm{M}$ TTX (68\% of the maximum before TTX treatment, $N=3$ neurons), suggesting that ReaChR can directly cause release at terminals.
Generation and characterization of ReaChR transgenic mice for circuit mapping

One disadvantage of using viral vectors for circuit mapping is that channelrhodopsin expression level varies across injections and across neurons in the same experiment. This results in variation in threshold for excitation and the need for normalization to control for infection efficacy in circuit mapping experiments. One approach to achieve more uniform ReaChR expression level is to express ReaChR transgenically. Thus, we generated and characterized mouse lines with ReaChR-mCitrine targeted to the Rosa26 locus using a construct whose expression is both Flp- and Cre-dependent (Fig. 3A). We evaluated expression in the ReaChR-mCitrine mice by crossing them to a Rosa-26 Flp mouse and injecting AAV-Syn-iCre into vS1. Fluorescence was visible at the injection site as well as from vS1 axons in vM1 (Fig. 3B; $17 \mathrm{~d}$ after injection). We then made whole-cell recordings in coronal sections of vS1 from L2/3 pyramidal neurons directly infected with AAV-Syn-iCre. Comparison of the current evoked while stimulating for $1 \mathrm{~s}$ with a $590 \mathrm{~nm}$ LED revealed more uniform 
A

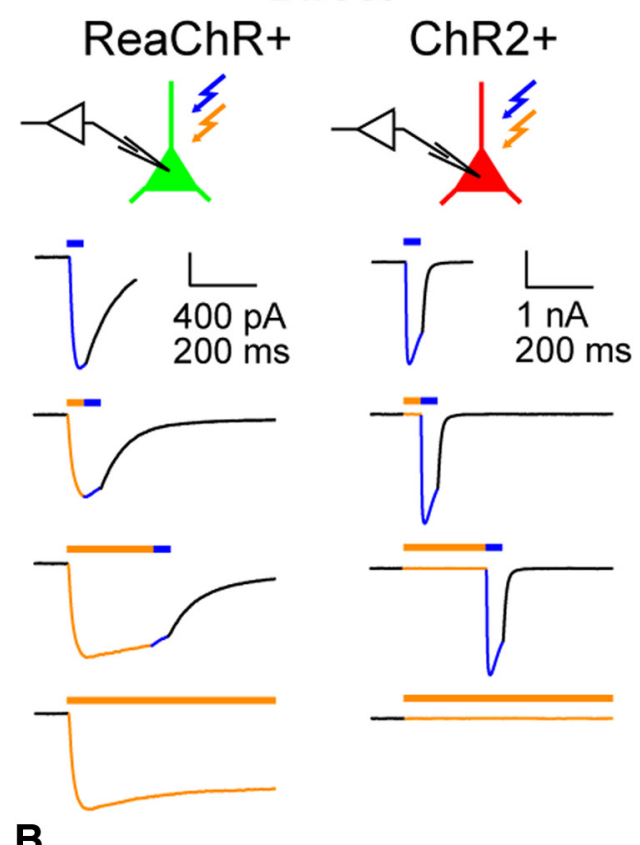

C Synaptic
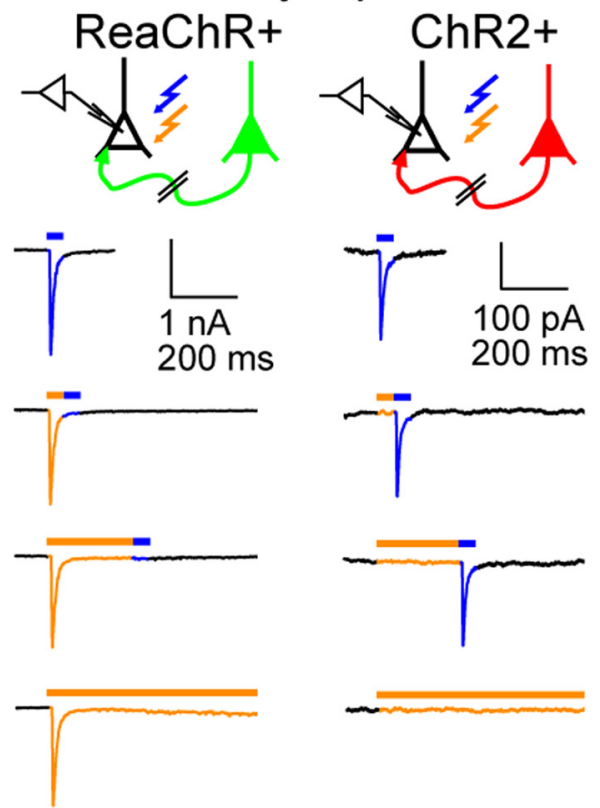

D

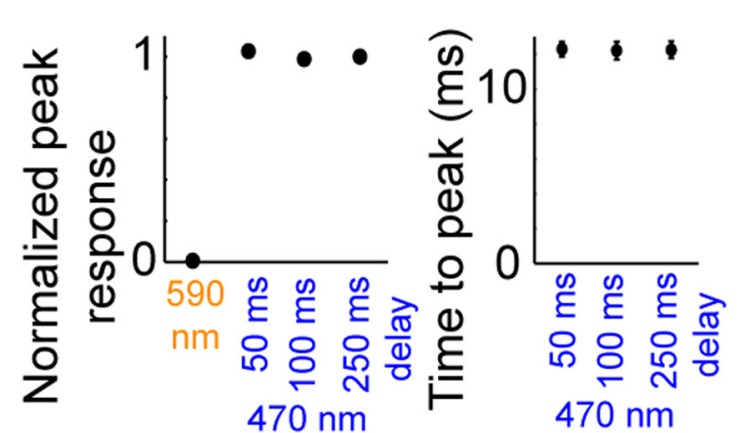

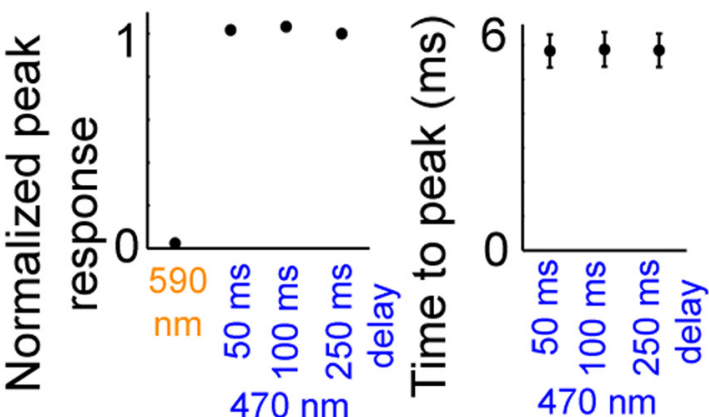

Figure 4. Synaptic responses from ReaChR + and ChR2 + axons can be evoked at separate times using multicolor stimuli. $A$, Direct responses of ReaChR to various photostimuli. Responses to 50 $\mathrm{ms}$ of $470 \mathrm{~nm}$ (top row), or 50 or $250 \mathrm{~ms}$ of $590 \mathrm{~nm}$ followed by $470 \mathrm{~nm}$ (middle two rows). The $1 \mathrm{~s}$ pulse of $590 \mathrm{~nm}$ is shown last; 470 and $590 \mathrm{~nm}$ photostimuli are of matched photon flux (5.3 $\times$ $10^{15}$ photons $/ \mathrm{smm}^{2} ; \sim 2 \mathrm{~mW} / \mathrm{mm}^{2}$ ). Direct responses of ReaChR neuron onset when either color photostimulus begins and persist until light is off. In contrast, the direct response of a ChR2 + neuron begins only when the $470 \mathrm{~nm}$ photostimulus is initiated. B, Quantification of the direct ChR2 response to delayed $470 \mathrm{~nm}$ stimulation shows that the peak response (SEM, smaller than symbol) and kinetics are not affected by the length of previous $590 \mathrm{~nm}$ photostimuli. $N=5$ neurons. $C$, When the same photostimuli are delivered to ReaChR axons, synaptic responses are recorded a few milliseconds after the onset of either color photostimulus. In contrast, only the onset of $470 \mathrm{~nm}$ photostimuli results in an EPSC from ChR2 + axons. There is a rightward shift in the EPSC. D, Quantification of the synaptic response from ChR2 + axons. $N=11$ neurons.

responses when ReaChR was expressed transgenically (Fig. 3C; $N=7$ neurons), compared with higher variability when AAV was used to express ReaChR ( $N=5$ neurons).

\section{Selective photostimulation of ChR2}

ReaChR is excited by blue and orange light. How then can dualchannel CRACM experiments be performed? We hypothesized that, because ReaChR + axons could be transiently and reversibly inactivated by stimulation with orange light, this would make them unexcitable to later blue photostimuli. To test this, we delivered photostimuli at the two different wavelengths for ChR2 and ReaChR separately. Direct photostimulation of ReaChR+ neurons with $470 \mathrm{~nm}$, immediately following illumination at 590 $\mathrm{nm}$, did not produce an increase in the peak photocurrent (Fig. $4 A$ ). This suggests that switching from orange to blue light in a CRACM experiment would not produce additional EPSC $\mathrm{C}_{\mathrm{C}}$. Photocurrents evoked by $470 \mathrm{~nm}$ light in ChR2+ neurons were similar with and without previous exposure to $590 \mathrm{~nm}$ light (Fig. $4 A, B$ ). ChR2 currents triggered by $470 \mathrm{~nm}$ light after $50 \mathrm{~ms}$ of $590 \mathrm{~nm}$ light were $101.3 \pm 0.9 \%$ of peak, normalized to the response at $250 \mathrm{~ms}$ delay $(N=5, p=0.24, t$ test; for $100 \mathrm{~ms}$ delay, $99.8 \pm 0.2 \%, p=0.81, t$ test). This suggests that ChR2-positive axons in a CRACM experiment would be unaffected by orange light.

We next investigated interactions between the two photostimuli in the context of CRACM experiments. Photostimulation of ReaChR + axons with $470 \mathrm{~nm}$ light immediately following illumination at $590 \mathrm{~nm}$ for 50,100 , or $250 \mathrm{~ms}$ did not produce a second $\mathrm{EPSC}_{\mathrm{C}}$, as prestimulation with orange light effectively inactivates ReaChR + axons (Fig. 4C). In contrast, photostimulation of ChR2 + axons at $470 \mathrm{~nm}$ produced similar amplitude EPSC $_{\mathrm{C}}$ with and without prestimulation with orange light (Fig. $4 C, D)$. Normalized EPSCs were $101.7 \pm 1.6 \%$ at $50 \mathrm{~ms}$ delay $(N=11, p=0.39, t$ test; $103.3 \pm 1.5 \%, p=0.26, t$ test at $100 \mathrm{~ms}$ delay compared with 250 ms delay). The EPSC $_{C}$ onset and timeto-peak for both direct and synaptic responses of ChR2 to $470 \mathrm{~nm}$ photostimulation were also not influenced by prestimulation. Thus, using sequential orange $\rightarrow$ blue photostimulation allows 
A

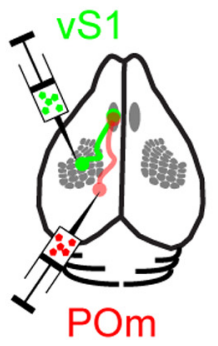

C

\section{Viral expression}
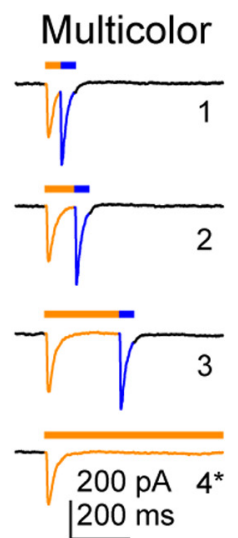

F

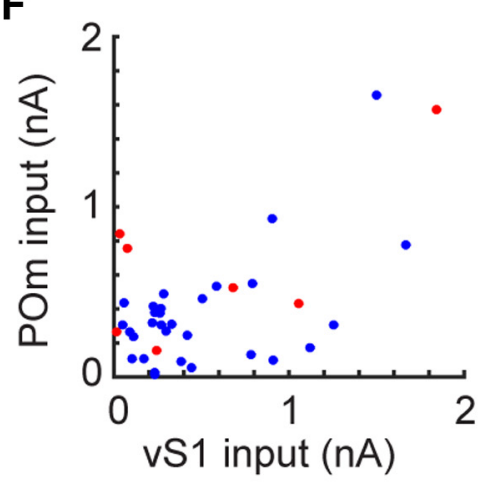

B

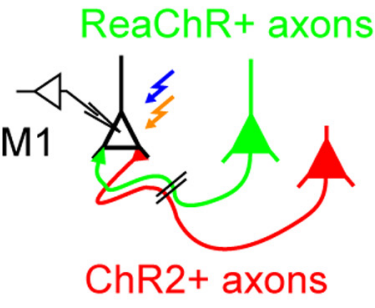

D

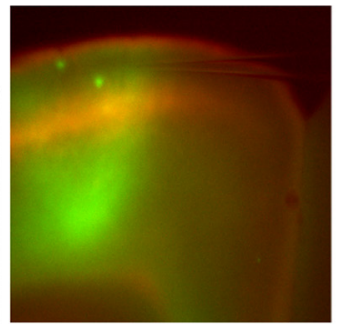

E

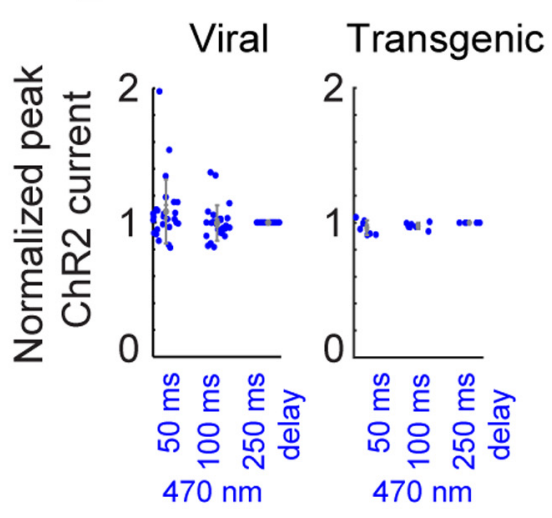

Subtracted
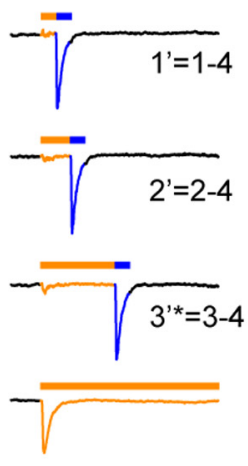

G

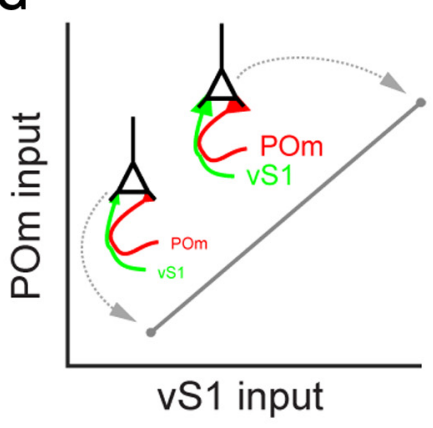

H

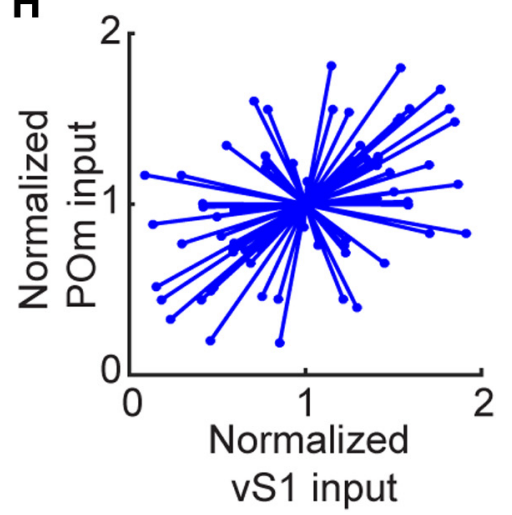

Figure 5. Synaptic inputs to a single vM1 neuron from vS1 and POm are sequentially excited by ReaChR and ChR2.A, ReaChR-mCitrine is expressed in vS1, and ChR2-tdtomato is expressed in POm. AAV injection into vS1 is either AAV-ReaChR-mCitrine (for wild-type mice) or AAV-Syn-iCre (for heterozygous Rosa26-ReaChR-mCitrine (+ / - ); Rosa26-Flp (+/-) mice). B, Bright-field (left) and fluorescence (right) images of vS1 (green) and POm (red) axons in vM1. Recordings are made from L2/3 pyramidal neurons in vM1 where the two projections overlap. $\boldsymbol{C}$, Multicolor stimuli of Figure 4 are delivered, revealing synaptic responses at two different times (left column). The prolonged $590 \mathrm{~nm}$ stimulus (trace 4) is subtracted from the first three stimulus patterns (traces 1-3) to reveal the ChR2 response alone, and the amplitude is compared by overlaying these three (aligned at bottom right). $\boldsymbol{F}-\boldsymbol{H},{ }^{*}$ Traces used for quantification. $\boldsymbol{D}$, Example recording from transgenic mouse demonstrates that the approach is effective for viral and transgenic expression. $E$, The peak ChR2-evoked EPSC ${ }_{C}$, normalized to the EPSC $C_{C}$ evoked following $250 \mathrm{~ms}$ of $590 \mathrm{~nm}$, is consistent across all three interstimulus intervals. $N=30$ neurons (virus) and $N=7$ neurons (transgenic). $F$, The EPSC amplitudes for POm and vS1 inputs are plotted (quantified from $3^{\prime *}$ and $4^{*}$, respectively). Each point represents the pair of input strengths to a single neuron. Viral ReaChR expression (blue points), $N=30$ neurons, $p=0.002, R^{2}=0.30$ (Pearson correlation coefficient with linear fit). Transgenic ReaChR expression (red points), $N=7$, provided for comparison only. $\mathbf{G}, \boldsymbol{H}$, Normalized EPSC ${ }_{C}$ amplitudes, with current amplitudes normalized for pairs of neurons recorded in the same slice. Each pair of points connected by a line represents a pair of neurons. $G$, Diagram illustrates a pair of neurons from the same slice where the neuron receiving stronger vS1 input also receives stronger POm input. Input is normalized to the average input strength of the pair (thus making the points equal amounts $>1$ and $<1$ ). $\boldsymbol{H}$, Comparison of normalized input strength to all neuron pairs for viral ReaChR expression (blue) $(N=34$ neuron pairs; $p=0.0164$, Wilcoxon signed rank test).

sequential activation of synaptic pathways defined by ReaChR and ChR2 expression.

\section{Mapping convergence of sensory inputs in the motor cortex} Ascending sensory information is topographically represented in vS1, with single barrels primarily responsive to touch of a single whisker (Woolsey and Van der Loos, 1970; Fox, 2008). The POm nucleus of the thalamus is part of an ascending sensory pathway characterized by slower, multiwhisker responses (Diamond et al., 1992). Axons from vS1 and POm each excite pyramidal neurons in L2/3 of vM1 (Hooks et al., 2013), but it is unknown whether these inputs are correlated at the level of single neurons. To test whether our approach would permit independent excitation of two synaptic pathways, we expressed ReaChR and ChR2 in vS1 and POm, respectively, and recorded from pyramidal neurons in regions of vM1 where ax- 
A

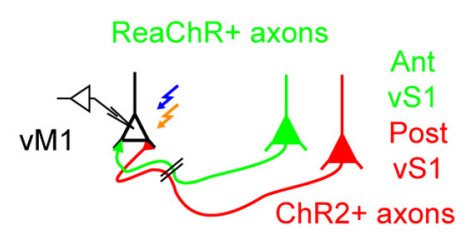

B

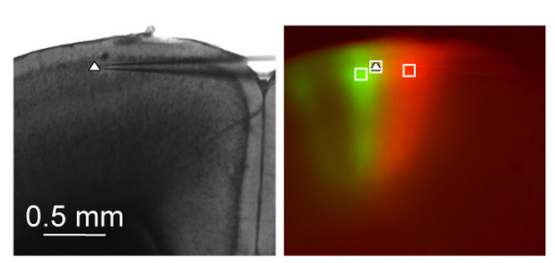

C Multicolor

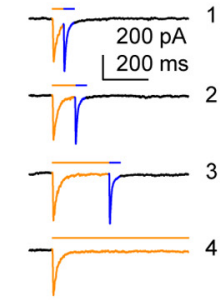

D

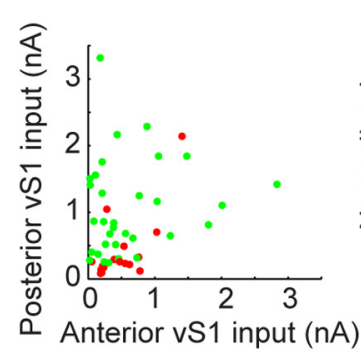

E

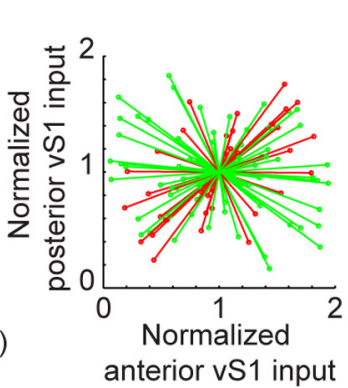

F

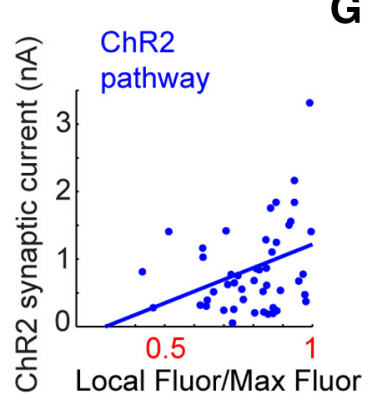

G

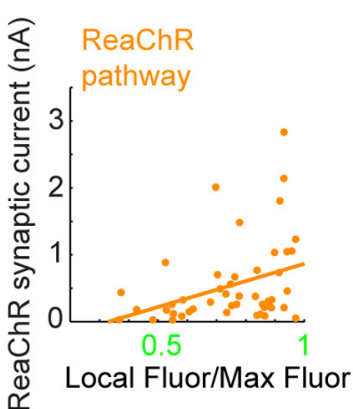

Figure 6. Single vM1 neurons integrate somatosensory input from across broad topographic regions of vS1. A, AAV-ReaChR-mCitrine and AAV-ChR2-tdtomato are expressed in anterior and posterior vS1, respectively. $\boldsymbol{B}$, Bright-field (left) and fluorescence (right) images indicate the topographically adjacent locations of inputs from topographically adjacent injections into anterior (green) and posterior (red) vS1. Recordings are made from L2/3 pyramidal neurons in vM1 between the two projections. For each neuron, three white boxes are used to quantify fluorescence near the soma of the recorded neuron, and the maximal red and green axonal fluorescence. $\mathbf{C}$, Example responses of anterior vS1 (ReaChR + ) and posterior vS1 (ChR2 + ) axons to various photostimuli. D, The EPSC amplitudes for inputs from anterior and posterior v 51 are plotted. Each point indicates the pair of input strengths to a single neuron. Green dots indicate conditions where anterior v 1 expressed ReaChR and posterior vS1 expressed ChR2. In a subset of cases (red dots, $N=16$ ), injection locations were reversed. The amplitude for $250 \mathrm{~ms}$ interstimulus interval is used for the ChR2 response. $N=47$ neurons, $p=0.100, R^{2}=0.06$ (Pearson correlation coefficient). $E$, Normalized EPSC ${ }_{C}$ amplitudes, with current amplitudes normalized for pairs of neurons recorded in the same slice; each pair of points connected by a line represents a pair of neurons ( $N=52$ neuron pairs; $p=0.4054$, Wilcoxon signed rank test). Red points indicate cases where the injection locations were reversed. $\boldsymbol{F}, \mathbf{G}$, Location in vM1 of the recorded L2/3 neuron had a significant effect on the amplitude of input from each pathway. Current amplitudes for a given pathway are generally larger when recording near the point of maximal fluorescence. Synaptic input for ChR2 + axons (left) is plotted against the local red fluorescence near the soma, as a fraction of the maximal red fluorescence in that slice ( $\left.p=0.012, R^{2}=0.13\right)$. ReaChR ${ }^{+}$axons (right) are plotted similarly for green fluorescence $\left(p=0.014, R^{2}=0.12\right)$. Three white boxes represent areas used to quantify fluorescence. $N=$ 47 neurons for all panels.

ons from POm and vS1 overlapped (Fig. $5 A, B$ ). Thalamic injections were targeted to posterior thalamic sites in POm as previously described (Petreanu et al., 2009; Hooks et al., 2013), and injection site targeting was verified both by examination of the injection site as well as the characteristic axonal lamination pattern in L1 and L5.

When we stimulated with orange light followed by blue light, postsynaptic excitatory synaptic responses $\left(\right.$ EPSC $\left._{C}\right)$ occurred at two different times (Fig. 5C, trace 1-3). After removal of the ReaChR-mediated EPSC $_{\mathrm{C}}$ (vS1 axons) from the ChR2-mediated EPSC $_{C}$ (POm axons) by subtracting the response during prolonged $590 \mathrm{~nm}$ stimulation (Fig. 5C, trace 4), the synaptic response triggered by vS1 axons alone (Fig. $5 C$, traces $1^{\prime}-3^{\prime}$ ) were similar $(N=30,108.2 \pm 4.1 \%$ compared with $250 \mathrm{~ms}$ delay, $p=$ $0.051, t$ test; $99.3 \pm 2.3 \%, 100 \mathrm{~ms}$ compared with $250 \mathrm{~ms}, t$ test, $p=0.743)$. This approach was also effective when ReaChR was expressed transgenically by vS1 injection of AAV expressing Cre instead of ReaChR. Photostimulation with orange and blue light evoked separate $\mathrm{EPSC}_{\mathrm{C}}$ from ReaChR+ and ChR2+ axons, showing that the ReaChR transgenic mouse exhibits a relatively high and uniform expression of ReaChR sufficient for two channel circuit mapping experiments. ChR2-mediated EPSC $_{C}$ at all interstimulus intervals were also consistent (Fig. $5 D, E$ ). The viral and transgenic approaches directly show that vS1 and POm afferents in vM1 converge on individual neurons (Hooks et al., 2013).

We tested whether the strength of input from one pathway predicted the strength of input from the other. Such specific connectivity might explain why the responses of neighboring neu- rons of the same type differ. We therefore measured whether neurons receiving larger amounts of input from one pathway (vS1) would also receive larger amounts of input from a second pathway (POm). We plotted the EPSC $_{\mathrm{C}}$ amplitudes for vS1 and POm input to single neurons and found that the peak current was correlated (Fig. 5F, blue points; Pearson correlation coefficient: $R^{2}=0.30 ; p=0.002$ ). For comparison, we also plotted neurons from the same experiment in the transgenic mice (red points, $N=7$ ), although there were insufficient data for statistical testing. The general absence of points along the axis suggests that there are few vM1 neurons that receive only vS1 or POm input exclusively.

Because an artificial positive correlation might be produced by differences in viral injections, resulting in high expression levels of ReaChR and ChR2 in one animal and weaker expression of ReaChR and ChR2 in another, we normalized synaptic strength in each pair of neurons recorded in each brain slice. For a pair of neurons recorded in the same slice, the synaptic strength was normalized to the mean of the two inputs, giving a range of 0-2 for vS1 or POm input, and plotted the pair with a line between them (Fig. 5G). Pairs going from the bottom left to the top right indicate a positive correlation; pairs going from the top left to the bottom right suggest a negative correlation. Thus, for a given pair of neurons in the same experiment, the neuron receiving higher vS1 input was typically also the neuron receiving higher POm input (Fig. $5 \mathrm{H}$, blue points; 24 of 34 pairs; $p=$ 0.0164 , Wilcoxon signed rank test). This finding suggests that a subset of vM1 neurons in $\mathrm{L} 2 / 3$ receive strong input from both $\mathrm{vS} 1$ 
and POm and thus may be specialized for sensory processing in the context of motor control.

We next applied our photostimulation technique to mapping inputs from different regions of vS1 to vM1. Somatosensory cortex in mouse is topographically organized, with individual vibrissae in the whisker pad represented as individual barrel columns in primary somatosensory ("barrel") cortex, and somatic somatosensory areas anterior and medial. Anatomical tracing studies have revealed a general topographic arrangement of vS1 projections in vM1, with more anterior vS1 injections projecting more laterally and posterior vS1 injections more medial within vM1 (Matyas et al., 2010; Mao et al., 2011). However, because of the overlap of the vS1 projection zones in vM1 and the widths of individual vM1 neuron dendrites, it is not clear the degree to which single vM1 neurons maintain the somatotopic organization of vS1 or integrate input from across somatosensory cortex.

We injected AAV-ReaChR-mCit and AAV-ChR2-tdtomato into anterior and posterior regions of vS1, respectively, separated by $0.75 \mathrm{~mm}$ (Fig. $6 A, B$ ). Each infection volume covered several barrel columns, but the volumes were largely nonoverlapping. Overlap in regions between the two injection sites is unlikely to contribute significantly to the synaptic currents measured, as most high-expressing ReaChR+ or $\mathrm{ChR} 2+$ neurons are found near the center of the injection sites. In some cases, injection locations were reversed (Fig. 6, green vs red points). We then recorded from $\mathrm{L} 2 / 3$ pyramidal neurons in regions of $\mathrm{vM} 1$ where axons arising from both parts of vS1 overlapped. As before, experiments revealed that both populations of axon can be independently photostimulated (Fig. 6C). Our data show that all neurons receiving input from one region of vS1 also received input from other region of vS1 (Fig. $6 D, E$ ). The strength of synaptic input was correlated with the local density of axons from anterior (green) or posterior (red) vS1 (Fig. $6 F, G$ ). When normalized current was compared as before, we did not find a correlation between pairs of neurons in the same experiment, with the neuron receiving higher anterior vS1 input also receiving higher posterior vS1 input in 29 of 52 pairs ( $p=0.405$, Wilcoxon signed rank test, Fig. $6 E$ ). These data suggest that vM1 neurons integrate somatosensory input from a large area of vS1.

\section{Discussion}

We have developed a method for activating two intermingled axonal populations independently. The method relies on two light-activated channels with distinct excitation spectra expressed in separate populations of axons. Axons expressing the red-shifted channel, ReaChR, can be activated alone using orange light. Axons expressing the blue-shifted channel can be activated independently after inactivation of ReaChR + axons with preillumination with orange light. Thus, sequential orange then blue photostimulation allows activation of synaptic pathways defined by ReaChR and ChR2 expression without crosstalk. We note that prolonged photostimulation of ReaChR + axons could be used to inactivate axonal projections in vivo.

Mammalian neural circuits consist of many brain areas, containing multiple cell types with diverse local and long-range inputs and outputs. Individual neurons may integrate more than 10 pathways (Wickersham et al., 2007; Marshel et al., 2010). These circuits are connected in a specific manner, shaped by molecular mechanisms, but their computational power relies on refinement by experience (Katz and Shatz, 1996; Flavell and Greenberg, 2008), resulting in unique "connectomes" for each brain (Seung, 2009; Bock et al., 2011). To unravel connectivity at the level of individual neurons, it is imperative to independently stimulate multiple types of afferents. This enables new types of neural circuit analysis, including comparing the strengths of different types of input at the level of individual neurons. Beyond circuit analysis, our approach may probe short latency interactions of two synaptic inputs. Inactivation of axons by prolonged photostimulation may have applications for experiments where light-gated axonal inactivation may allow silencing of specific projections selected by targeting of light instead of silencing all output from the soma.

Our approach for dual-channel photostimulation has some caveats. First, our approach requires activation of the ReaChR+ population before the $\mathrm{ChR} 2+$ population. Stimulation in the opposite order requires separate animals with the channels injected in the opposite locations. Second, the slow kinetics of ReaChR are not ideal for high-frequency stimulation. Third, the neurons expressing light-gated channels must have appropriate intrinsic excitability such that their axons will not fire repetitively in response to prolonged photostimuli. We show this to be the case for pyramidal neurons (Figs. 4, 5, and 6), but prolonged photostimulation of ChR2 expressed in SOM-positive neocortical interneurons, for example, resulted in repetitive activity, not depolarization block.

Future strategies for dual-channel photostimulation might rely on selecting an ultrasensitive ChR2 variant for activation during blue light stimulation. The ultrasensitive channel would respond to brief, low-intensity stimulation at $470 \mathrm{~nm}$ and thus might permit suprathreshold activation in one pathway while keeping the ReaChR+ axons below threshold. Achieving consistent expression of channels in different cell types, such as by a transgenic approach in our ReaChR mouse or Ai32 mice (Madisen et al., 2012), will help in making the difference between subthreshold and suprathreshold blue light stimulation more consistent. Balancing illumination in brain slices is straightforward but may be more challenging in vivo. Because orange light penetrates tissue further than blue light, this approach may work, but direct testing is needed.

We used 2CRACM to study convergence of sensory inputs to individual L2/3 vM1 neurons. vS1 and POm inputs excite the same individual neurons, and the strength of the two inputs is positively correlated. The subset of neurons that receive strong input from both may be functionally specialized for processing sensory information for motor control, such as the touchresponsive neurons characterized by imaging studies in vM1 during a whisker-dependent object localization task (Huber et al., 2012). Our examination of sensory input from two different locations in vS1 shows that individual vM1 pyramidal neurons integrate input from across the somatotopic map. As implied by multiwhisker responses in microstimulation experiments (Brecht et al., 2004; Hooks et al., 2011; Tennant et al., 2011), our results suggest that the integration of somatosensory information from multiple locations of vS1 in single vM1 neurons precludes the existence of large numbers of highly whisker-specific neurons in superficial layers of vM1. It will be interesting to identify two classes of input where afferent strength is negatively correlated, as this would suggest the existence of two cell types with distinct functional responses that could be ascribed to their connectivity.

\section{References}

Arenkiel BR, Peca J, Davison IG, Feliciano C, Deisseroth K, Augustine GJ, Ehlers MD, Feng G (2007) In vivo light-induced activation of neural circuitry in transgenic mice expressing channelrhodopsin-2. Neuron 54: 205-218. CrossRef Medline 
Bock DD, Lee WC, Kerlin AM, Andermann ML, Hood G, Wetzel AW, Yurgenson S, Soucy ER, Kim HS, Reid RC (2011) Network anatomy and in vivo physiology of visual cortical neurons. Nature 471:177-182. CrossRef Medline

Brecht M, Krauss A, Muhammad S, Sinai-Esfahani L, Bellanca S, Margrie TW (2004) Organization of rat vibrissa motor cortex and adjacent areas according to cytoarchitectonics, microstimulation, and intracellular stimulation of identified cells. J Comp Neurol 479:360-373. CrossRef Medline

Diamond ME, Armstrong-James M, Ebner FF (1992) Somatic sensory responses in the rostral sector of the posterior group (POm) and in the ventral posterior medial nucleus (VPM) of the rat thalamus. J Comp Neurol 318:462-476. CrossRef Medline

Dymecki SM, Kim JC (2007) Molecular neuroanatomy's “Three Gs”: a primer. Neuron 54:17-34. CrossRef Medline

Flavell SW, Greenberg ME (2008) Signaling mechanisms linking neuronal activity to gene expression and plasticity of the nervous system. Annu Rev Neurosci 31:563-590. CrossRef Medline

Fox K (2008) Barrel cortex, Ed 1. Cambridge, United Kingdom: Cambridge.

Harvey CD, Coen P, Tank DW (2012) Choice-specific sequences in parietal cortex during a virtual-navigation decision task. Nature 484:62-68. CrossRef Medline

Hooks BM, Mao T, Gutnisky DA, Yamawaki N, Svoboda K, Shepherd GM (2013) Organization of cortical and thalamic input to pyramidal neurons in mouse motor cortex. J Neurosci 33:748-760. CrossRef Medline

Hooks BM, Hires SA, Zhang YX, Huber D, Petreanu L, Svoboda K, Shepherd GM (2011) Laminar analysis of excitatory local circuits in vibrissal motor and sensory cortical areas. PLoS Biol 9:e1000572. CrossRef Medline

Huber D, Gutnisky DA, Peron S, O'Connor DH, Wiegert JS, Tian L, Oertner TG, Looger LL, Svoboda K (2012) Multiple dynamic representations in the motor cortex during sensorimotor learning. Nature 484:473-478. CrossRef Medline

Kaneko T, Caria MA, Asanuma H (1994) Information processing within the motor cortex: II. Intracortical connections between neurons receiving somatosensory cortical input and motor output neurons of the cortex. J Comp Neurol 345:172-184. CrossRef Medline

Katz LC, Shatz CJ (1996) Synaptic activity and the construction of cortical circuits. Science 274:1133-1138. CrossRef Medline

Kim J, Matney CJ, Blankenship A, Hestrin S, Brown SP (2014) Layer 6 corticothalamic neurons activate a cortical output layer, layer 5a. J Neurosci 34:9656-9664. CrossRef Medline

Klapoetke NC, Murata Y, Kim SS, Pulver SR, Birdsey-Benson A, Cho YK, Morimoto TK, Chuong AS, Carpenter EJ, Tian Z, Wang J, Xie Y, Yan Z, Zhang Y, Chow BY, Surek B, Melkonian M, Jayaraman V, ConstantinePaton M, Wong GK, et al. (2014) Independent optical excitation of distinct neural populations. Nat Methods 11:338-346. CrossRef Medline

Lin JY, Knutsen PM, Muller A, Kleinfeld D, Tsien RY (2013) ReaChR: a red-shifted variant of channelrhodopsin enables deep transcranial optogenetic excitation. Nat Neurosci 16:1499-1508. CrossRef Medline

Madisen L, Mao T, Koch H, Zhuo JM, Berenyi A, Fujisawa S, Hsu YW, Garcia AJ 3rd, Gu X, Zanella S, Kidney J, Gu H, Mao Y, Hooks BM, Boyden ES, Buzsáki G, Ramirez JM, Jones AR, Svoboda K, Han X, et al. (2012) A toolbox of Cre-dependent optogenetic transgenic mice for light-induced activation and silencing. Nat Neurosci 15:793-802. CrossRef Medline

Mao T, Kusefoglu D, Hooks BM, Huber D, Petreanu L, Svoboda K (2011) Long-range neuronal circuits underlying the interaction between sensory and motor cortex. Neuron 72:111-123. CrossRef Medline

Marshel JH, Mori T, Nielsen KJ, Callaway EM (2010) Targeting single neuronal networks for gene expression and cell labeling in vivo. Neuron 67:562-574. CrossRef Medline
Mattis J, Tye KM, Ferenczi EA, Ramakrishnan C, O'Shea DJ, Prakash R, Gunaydin LA, Hyun M, Fenno LE, Gradinaru V, Yizhar O, Deisseroth K (2012) Principles for applying optogenetic tools derived from direct comparative analysis of microbial opsins. Nat Methods 9:159-172. CrossRef Medline

Matyas F, Sreenivasan V, Marbach F, Wacongne C, Barsy B, Mateo C, Aronoff R, Petersen CC (2010) Motor control by sensory cortex. Science 330: 1240-1243. CrossRef Medline

Nagel G, Szellas T, Huhn W, Kateriya S, Adeishvili N, Berthold P, Ollig D, Hegemann P, Bamberg E (2003) Channelrhodopsin-2, a directly lightgated cation-selective membrane channel. Proc Natl Acad Sci U S A 100: 13940-13945. CrossRef Medline

O'Connor DH, Peron SP, Huber D, Svoboda K (2010) Neural activity in barrel cortex underlying vibrissa-based object localization in mice. Neuron 67:1048-1061. CrossRef Medline

Ohno S, Kuramoto E, Furuta T, Hioki H, Tanaka YR, Fujiyama F, Sonomura T, Uemura M, Sugiyama K, Kaneko T (2012) A morphological analysis of thalamocortical axon fibers of rat posterior thalamic nuclei: a single neuron tracing study with viral vectors. Cereb Cortex 22:2840-2857. CrossRef Medline

Paxinos G, Franklin HBJ (2004) The mouse brain in stereotaxic coordinates. Compact Ed 2. Amsterdam: Elsevier.

Petreanu L, Huber D, Sobczyk A, Svoboda K (2007) Channelrhodopsin-2assisted circuit mapping of long-range callosal projections. Nat Neurosci 10:663-668. CrossRef Medline

Petreanu L, Mao T, Sternson SM, Svoboda K (2009) The subcellular organization of neocortical excitatory connections. Nature 457:1142-1145. CrossRef Medline

Seung HS (2009) Reading the book of memory: sparse sampling versus dense mapping of connectomes. Neuron 62:17-29. CrossRef Medline

Shepherd GM, Pologruto TA, Svoboda K (2003) Circuit analysis of experience-dependent plasticity in the developing rat barrel cortex. Neuron 38:277-289. CrossRef Medline

Suter BA, O’Connor T, Iyer V, Petreanu LT, Hooks BT, Kiritani T, Svoboda K, Shepherd GM (2010) Ephus: multipurpose data acquisition software for neuroscience experiments. Front Neurosci 4:100. CrossRef Medline

Tennant KA, Adkins DL, Donlan NA, Asay AL, Thomas N, Kleim JA, Jones TA (2011) The organization of the forelimb representation of the C57BL/6 mouse motor cortex as defined by intracortical microstimulation and cytoarchitecture. Cereb Cortex 21:865-876. CrossRef Medline

Wickersham IR, Lyon DC, Barnard RJ, Mori T, Finke S, Conzelmann KK, Young JA, Callaway EM (2007) Monosynaptic restriction of transsynaptic tracing from single, genetically targeted neurons. Neuron 53:639647. CrossRef Medline

Woolsey TA, Van der Loos H (1970) The structural organization of layer IV in the somatosensory region (SI) of mouse cerebral cortex: the description of a cortical field composed of discrete cytoarchitectonic units. Brain Res 17:205-242. CrossRef Medline

Yizhar O, Fenno LE, Prigge M, Schneider F, Davidson TJ, O'Shea DJ, Sohal VS, Goshen I, Finkelstein J, Paz JT, Stehfest K, Fudim R, Ramakrishnan C, Huguenard JR, Hegemann P, Deisseroth K (2011) Neocortical excitation/inhibition balance in information processing and social dysfunction. Nature 477:171-178. CrossRef Medline

Zhang F, Prigge M, Beyrière F, Tsunoda SP, Mattis J, Yizhar O, Hegemann P, Deisseroth K (2008) Red-shifted optogenetic excitation: a tool for fast neural control derived from Volvox carteri. Nat Neurosci 11:631-633. CrossRef Medline 